\title{
IAMJ
}

INTERNATIONAL

AYURVEDIC

MEDICAL JOURNAL

do) $\bigcirc$ (1)

Review Article

ISSN: 2320-5091

Impact Factor: 6.719

\section{UNDERSTANDING THE ETIOPATHOGENESIS AND PATHOPHYSIOLOGY OF RENAL CALCULI}

\author{
Harsh Sharma ${ }^{1}$, Rajesh Kumar Sharma ${ }^{2}$, Dinesh Chandra Sharma ${ }^{3}$, Vinod Meena ${ }^{4}$ \\ ${ }^{1}$ M.D. Scholar, P.G. Department of Kriya Sharir, DSRRAU, Jodhpur, Rajasthan, India \\ ${ }^{2}$ Professor \&amp; H.O.D., P.G. Department of Kriya Sharir, DSRRAU, Jodhpur, Rajasthan, India \\ ${ }^{3}$ Associate Professor, P.G. Department of Kriya Sharir, DSRRAU, Jodhpur, Rajasthan, India \\ ${ }^{4}$ M.D. Scholar, P.G. Department of Kriya Sharir, DSRRAU, Jodhpur, Rajasthan, India
}

Corresponding Author: Harsh9982@gmail.com

https://doi.org/10.46607/iamj1509112021

(Published Online: November 2021)

Open Access

(C) International Ayurvedic Medical Journal, India

Article Received: 15/08//2021 - Peer Reviewed: 28/08/2021 - Accepted for Publication: 31/08/2021

Check for updates

\begin{abstract}
Calculus (Stone) is a polycrystalline aggregate made up of different quantities of the crystalloid and organic matrix. Urine calculus is a stone-like formation made up of urine salts held together by a colloid matrix or organic elements. It has a nucleus or nidus around which concentric layers of urinary salts are formed, giving it a stone-like appearance. Urolithiasis (from Greek oûron, "urine," and lithos, "stone") is a urinary system pathology in which urinary crystalloids clump together anywhere in the urinary tract, from the kidney to the bladder. The kidneys play a critical role in excreting waste products from the body, but various problems can disrupt the urinary system's crucial activities and cause illnesses, one of which is urolithiasis. Urinary calculi are worldwide in distribution but are particularly common in some geographic locations such as in parts of the United States, South Africa, India and SouthEast Asia. Renal calculi are characterised clinically by colicky pain (renal colic) as they pass down along the ureter and manifest by haematuria.

This article focuses on the etiopathogenesis of Renal Stone, predisposing factors, and its pathophysiology for a better understanding of the disease so that its formation can be prevented, and the formed calculi can be treated with better knowledge.
\end{abstract}


Keywords: Urinary Stones, Oxalates, Predisposing factors: urinary crystalloids, Hyperoxaluria, Hypercalciuria, Super-Saturation Theory, Nucleation Theory, Randall's plaque

\section{INTRODUCTION}

\section{Urinary Calculi}

Urinary calculi are polycrystalline aggregates composed of varying amounts of crystalloid and a small amount of organic matrix. Stone formation requires saturated urine that is dependent on $\mathrm{pH}$, ionic strength, solute concentration, and complexation.

There are five major types of urinary stones which are:

1. Calcium oxalate,

2. Calcium phosphate,

3. Struvite (magnesium ammonium phosphate),

4. Uric acid, and

5. Cystine.

The most common types are composed of calcium $(85 \%)$, and for that reason, most urinary stones are radiopaque on plain abdominal radiographs. Uric acid stones frequently are composed of a combination of uric acid and calcium oxalate and thus are frequently radiopaque, though pure uric acid stones are radiolucent.

Cystine stones frequently have a smooth-edged ground-glass appearance and are radiolucent. Geographic factors contribute to the development of stones.

High humidity and elevated temperatures appear to be contributing factors, and the incidence of symptomatic ureteral stones is greatest in such areas during hot summer months. Higher incidence rates of stones have also been associated with a sedentary lifestyle, hypertension, carotid calcification, and cardiovascular disease. High protein and salt intake, as well as inadequate hydration, appear to be the most important dietary factors in the development of urinary stones. Genetic factors may contribute to urinary stone formation.

While approximately $50 \%$ of calcium-based stones are thought to have a heritable component, other stone types are better characterized genetically. For example, cystinuria is an autosomal recessive disorder. Homozygous individuals have markedly increased excretion of cystine and frequently have numerous recurrent episodes of urinary stones. ${ }^{1}$

\section{Aetiology Of Urinary Stone: ${ }^{2}$}

Although the specific origin and process of stone development in the urinary system are unknown, the following conditions may contribute to urinary stone development: -

\section{1) Extrinsic factors:}

Extrinsic factors are those which include the factors which affect the body organs through the outside or external environment. These are the occupation, geography and diet of an individual.

\section{Occupation}

People with high socioeconomic status and a sedentary lifestyle are more vulnerable to this disease. According to a report, insufficient physical activity and oversaturation of urine may be key factors leading to the production of numerous urinary stones. Regular cooks, engine room employees, heavy chemical workers, drivers, and others who are exposed to high ambient temperatures may have a part in the production of stone.

\section{Geography3:}

Though urinary calculi are found all over the world, there are a few nations and locales that are more prone to this condition, and they are referred to as "stone zones." Diet, water, climate, and geographical location are the elements to blame. In India, two high-index belts have been identified.

i. One begins in Amritsar (Punjab) or the Northwest, includes Delhi and Agra, and concludes in Uttar Pradesh.

ii. The second begins on the west coast in Jamnagar (Gujarat) and extends inward to central India, ending at Jabalpur (Madhya Pradesh). Urolithiasis is quite common in the Saurashtra area of Gujarat.

\section{Diet:}

\section{High Protein Rich Diet ${ }^{4}$ :}

Proteins are responsible for the high production of uric acid and excess excretion in urine may cause the uric acid stone. 


\section{Deficiency of vitamin $A^{\mathbf{5}}$ :}

Causes desquamation of epithelium. These cells form a nidus for stone formation.

\section{Excessive administration of Vitamin-D:}

It may lead to calculi formation due to calcification within the kidney substance and the condition is known as ephrocalcinosis.

\section{Water Intake: ${ }^{6}$}

i. The volume of water intake: Less volume intake leads to concentrated urine and the urine becomes acidic, which is the good media for stone formation in certain cases.

- Hard water and mineral content of water: Hard water having calcium sulphate and absence of zinc predisposes to calcium crystallization that leads to stone formation.

- $\quad \operatorname{Food}^{7}$ : Some liquids and foods that contain rich oxalates and are -

Moderate amount: Apple juice, beer, cola, grapefruit juice, cranberry juice, almonds, asparagus, beef, greens, plums, cactus fruits, cashew nuts, currants, concord grapes, cranberries, raspberries, rhubarb, spinach and absence of zinc predisposes to calcium crystallization that leads to stone formation. A diet high in purines (red meat, fish, eggs), oxalates (rhubarb, strawberries, plums, spinach), and calcium (milk, ice cream tomatoes) result in the production of uric acid, oxalates, and calcium stone.

\section{Intrinsic factors ${ }^{8}$ :} Intrinsic factors are those which effects the body organs directly. Such of these are Hereditary, Age and Sex of an individual.

\section{a) Hereditary:}

i. Cystinuria is a homozygous recessive disease leading to the formation of cystine calculi.

ii. Urinary calcium excretion is more in the members of stone-forming families.

iii. Renal tubular acidosis is a hereditary condition leading to urolithiasis.

b) Age: Urolithiasis can strike at any age, although it is most frequent in the third and fourth decades of life. Urinary calculi are uncommon in children, however, infants born prematurely and administered frusemide, as well as patients in critical care units, are at a higher risk of developing urinary calculi.

c) Sex: Urolithiasis is more frequently found in males than in females. The male: female ratio is 41: 25 (Finlayson 1974). In females, stone formation is less because of low serum testosterone levels, but female children have most commonly oxalate stones.

\section{3) Predisposing factors:}

Predisposing factors are those that put an individual at risk of developing a problem (in this case, Renal Calculi or Stone). These may include genetics, life events, or temperament. Precipitating factors refer to a specific event or trigger to the onset of the current problem.

\section{a) Physical changes in urine?:}

\section{i. Urinary pH:}

The average $\mathrm{pH}$ of the urine is 5.85. Diet and medications have an impact on it. If the urine becomes contaminated with urea splitting bacteria, such as Proteus mirabilis, the urine becomes very alkaline due to the release of ammonia. Urinary calculi are formed by inorganic salts that are less soluble in alkaline media, such as calcium phosphate and magnesium ammonium phosphate (triple phosphate). As a result, the $\mathrm{pH}$ of urine is critical in the production of urinary calculi as well as in their treatment.

\section{ii. Altered urinary crystalloids and colloids:}

In urine, there are several crystalloids of various sorts. The presence of colloids in the urine, as well as the absorption process, keep these crystalloids in solution. Urine crystalloids include oxalate, calcium, cystine, uric acid, and others, whereas urinary colloids include mucin and chondroitin sulphuric acid. The presence of these elements increases the likelihood of stone formation.

- Urinary stones can occur when there is an imbalance in the crystalloid-colloid ratio - either an increase in the crystalloid level or a decrease in the colloid level. - Urinary stones may form if the colloids undergo any change, such as losing their solvent activity or sticky characteristic.

\section{iii. Urinary magnesium/calcium ratio:}

This most likely has a significant impact on stone 
formation. Diamox (acetazolamide) induces hypercalciuria and a reduction in the ratio. This is due to an increase in the occurrence of stone formation. The Thiazides, which have a significant impact on reducing the recurrence of stone formation by increasing this ratio.

\section{iv. Decreased urinary citrate:}

The typical citrate content in urine is between 300 and $900 \mathrm{mg} /$ day. Citrate in urine retains comparatively soluble calcium phosphate and carbonate in solution. Any decrease in citrate production results in the formation of insoluble calcium phosphate and carbonate. It is controlled by hormones and decreases during menstruation. Oestrogen increases the amount of citric acid in the urine, which reduces the amount of calcium in the urine.

\section{v. Urinary infection:}

Urinary calculi are favoured by infection. Because of the shorter length of the urethra, females are more prone to urinary tract infections. In roughly $80 \%$ of instances, stone development is accompanied by urinary tract infection. Staphylococci and E. coli are the most common bacteria detected in urinary stone nuclei. Organisms such as streptococcus, staphylococci, and proteus promote stone formation by:

- Splitting urea in the urine into ammonia and $\mathrm{CO}_{2}$, resulting in alkaline urine prone to the production of phosphatic calculi.

- Infection also causes an increase in the concentration of crystalloids, which may produce stone under some circumstances.

- Because infection changes the colloid components of the urine, the risks of stone formation increase.

b) Inadequate urinary drainage and urinary stasis:

i. Stones are more likely to develop when the free transit of urine is obstructed.

ii. Urinary stasis creates an ideal environment for bacterial development. It also causes the $\mathrm{pH}$ of the urine to move to the alkaline side.

iii. Stasis also increases the risk of urinary infection by allowing crystalloids to precipitate, which aids in the production of urinary stones.

\section{c) Metabolic factors:}

The persons who are born with metabolic errors of cystine, oxalates or uric acid, may develop calculi composed of one of any of these substances.

\section{d) Crystalluria: ${ }^{10}$}

\section{- Hyperoxaluria:}

Oxalate is a natural metabolic waste product that is somewhat insoluble and is derived from food. It is a key component of $70 \%$ of all renal stones; nevertheless, hyperoxaluria as a cause of such stone formation is uncommon. Oxalate is abundant in cabbage, rhubarb, spinach, tomato, black tea, and cocoa. Excessive use of ascorbic acid and orange juice increases urinary oxalate excretion. However, dietary oxalate is often poorly absorbed and does not have a significant role in the production of oxalate stones. In reality, restricting certain meals has only a little impact on the prevention of oxalate stones. It is classified into two types:

- Primary hyperoxaluria is a rare genetic condition that affects the metabolism of glycol-oxylic acid, which results in the formation of oxalate rather than other soluble end products. It's a major cause of nephrolithiasis in kids.

- Acquired hyperoxaluria is caused by pyridoxine insufficiency, ethylene glycol poisoning, small bowel illness with oxalate hyperabsorption, and methoxyflurane anaesthesia.

\section{- Hypercalciuria:}

One of the most prevalent causes of urolithiasis is this disorder. In most laboratories, the normal serum calcium concentration varies from $9.6 \mathrm{mg}$ to $10.9 \mathrm{mg} / 100$ $\mathrm{ml}$. On a typical diet, typical urine calcium excretion is between $200 \mathrm{mg}$ and $300 \mathrm{mg} /$ day. Milk and cheese are the most important calcium sources in the diet. Calcium absorption from the gut is also boosted by milk and dietary proteins. The existence or absence of calculi is not primarily determined by the presence or lack of hypercalciuria, since many people with no history of calculi excrete substantial amounts of urine calcium without producing calculi. 
- The main causes of hypercalciuria are -

- Primary hyperparathyroidism:

This syndrome occurs in about $2-5 \%$ of instances with renal stones. This cause should be excluded by a biochemical test in cases of numerous or recurring urinary calculi. This syndrome is characterised by improper serum calcium control. As a result, an increase in blood calcium concentration over the usual range increases the calcium burden on the kidney, which can result in hypercalciuria and stone formation. As a result, a parathyroid adenoma should be removed before treating urinary calculi.

\section{Multiple myeloma:}

It is a cell tumour that can cause a considerable amount of aberrant serum globulin to be produced, as well as the excretion of Bence Joenes protein in the urine.

\section{Pathogenesis of Renal calculi:}

Pathogenesis is the process by which a disease or disorder develops. It can include factors that contribute not only to the onset of the disease or disorder but also to its progression and maintenance, Pathogenesis of the urinary stones involves many theories which are enumerated in the following paragraphs.

\section{A. Super-Saturation Theory ${ }^{11}$ :}

Stone formation requires supersaturated urine. Supersaturation depends on urinary $\mathrm{pH}$, ionic strength, solute concentration and complexation.

\section{a) Solute concentration:}

The higher the concentration of two ions, the more likely it is that they will precipitate. Undersaturation and enhanced solubility arise from low ion concentration. As ion concentration rises, their activity product, known as the solubility product, approaches a critical threshold (Ksp). Concentrations over this amount are metastable, allowing crystal formation and heterogeneous nucleation to begin. The activity product eventually approaches the formation product as solutions grow more concentrated (Kfp). Beyond this limit, supersaturation levels are unstable, and spontaneous homogeneous nucleation may occur.

\section{b) Urinary $\mathbf{p H}$ :}

It may change dramatically during different physiological states of the body from relatively acid urine in first-morning urine to an alkaline tide noted after meals.

\section{c) Ionic strength:}

It is mostly determined by the relative concentration of monovalent ions. The activity coefficient reduces as ionic strength increases; the activity coefficient indicates the availability of a certain ion.

\section{d) Complexation:}

It affects the availability of certain ions. For example, sodium complexes with oxalate and lowers their free ionic form, whereas sulphates can combine with calcium crystals formation is influenced by a range of different urinary tract chemicals such as magnesium citrate, pyrophosphate, and a range of test metals. This inhibitor may operate at active crystal growth sites or as a solution inhibitor, similar to citrate. (Page 256 of Smith's General Urology).

\section{B. Nucleation Theory ${ }^{12}$ :}

Urinary stones may form as a result of crystals or foreign materials submerged in supersaturated urine. The same arguments that support it are used to refute this idea. Stones do not usually occur in persons who are hyper-excretes or who are dehydrated. Furthermore, 24-hour urine samples are entirely normal in terms of stone-forming ion concentration in many stone formers.

\section{Randall's plaque (microliths) ${ }^{\mathbf{1 3}}$ :}

According to Randall, the first lesion in the production of renal calculus is erosion at the apex of one of the renal papillae. The deposition of calcium on this erosion resulted in Randall's plaque, a lesion. This calcification serves as a nidus or nucleus for insoluble crystals to deposit and create the stone. Many researchers later concluded that most stones form as a result of the precipitation of crystals, such as calcium oxalate, on an organic matrix composed of amino acids and carbohydrates. Nidus can be formed by blood clots, clumps of epithelial cells, bacteria, or even pus cells. Foreign bodies and necrotic ischemic tissue can generate nidus and promote stone development.

\section{The Crystal Inhibitor Theory:}

It states that the production of calculi is caused by a lack of natural stone inhibitors such as magnesium, citrate, pyrophosphate, and a range of stress metals. This 
idea is not without flaws, since many persons who lack such inhibitors may never produce stones, while others who have an abundance of inhibitors paradoxically create stones.

\section{CONCLUSION}

Calcium oxalate is the major component of $70-80 \%$ of Renal Calculi. Both of these components i.e., calcium \& Oxalate have both dietary and endogenous sources. Oxalate is found in many foods but particularly found in rich quantities in Spinach, green leafy vegetables, and various fruits as mentioned above. Hyperoxaluria occurs in around $18 \%$ of kidney stone patients, and in the line of treatment it is advised to reduce the intake of oxalate-containing foods or co-ingesting calciumcontaining foods mentioned in order to have calcium oxalate bind together in the gastrointestinal tract as the oxalate absorption occurs in the stomach ${ }^{\mathbf{1 4}, 15}$

Increasing Fluid intake, decreasing urinary calcium, and uric acid excretion have been shown to reduce the stone recurrence in recurrent calcium oxalate stones.

\section{REFERENCES}

1. Maxine A. papadakis, Current medical diagnosis and treatment 2019, $58^{\text {th }}$ edition, Page 945

2. http://www.livestrong.com/article/320318-walkingkidney-stone

3. https://dilipraja.com/kidney-stone/

4. www.kidney.org/atoz/content/diet.cfm

5. Bailey \& Love's Short Practice of Surgery, Chapter 75, Page 1316, Edited by R.C.G. Russell, Norman S. Williams, Christopher J.K. Bulstrode; Edward Arnold Publishers Ltd., London, 24th Edition 2004. () S. Das, A concise textbook of Surgery, Chapter 49, Page 1072, Published by Dr S. Das, Kolkata, 6th Edition 2010. ()www.prep4usmle.com/forum/89437

6. www.kidneystoners.org/information/myths, S. Das, A concise textbook of Surgery, Chapter 49, Page 1071, Published by Dr S. Das, Kolkata, 6th Edition 2010.

7. https://www.emedicinehealth.com/kidney_stones/article_em.htm

8. Raguram Ganesamoni and Shrawan K. Singh, Epidemiology of stone disease in Northern India, Page no. 39, Urolithiasis, Basic Science and Clinical Practice.

9. S. Das, A concise textbook of Surgery, Chapter 49, Page 1072, Published by Dr S. Das, Kolkata, 6th
Edition 2010, Bailey \& Love's Short Practice of Surgery 27th Edition, Norman Williams, P Ronan O'Connell, Andrew McCaskie, Chapter 75, Page no. 1316

10. S. Das, A concise textbook of Surgery, Chapter 49, Page 1071, Published by Dr S. Das, Kolkata, 6th Edition 2010

11. Bailey \& Love's Short Practice of Surgery 27th Edition, Norman Williams, P Ronan O'Connell, Andrew McCaskie, Chapter 76, Page no. 1348

12. www.urologytoday.net, www.ncbi.nlm.nih.gov

13. S. Das, A concise textbook of Surgery, Chapter 49, Page 1073-1074, Published by Dr S. Das, Kolkata, 6th Edition 2010, Bailey \& Love's Short Practice of Surgery 27th Edition, Norman Williams, P Ronan O'Connell, Andrew McCaskie, Chapter 75, Page no. 13161317

14. Hautmann RE. The Stomach: a new and powerful oxalate absorption site in man. J. Urol. 1993;149(6):14014

\section{Source of Support: Nil \\ Conflict of Interest: None Declared}

How to cite this URL: Harsh Sharma et al: Understanding The Etiopathogenesis And Pathophysiology Of Renal Calculi. International Ayurvedic Medical Journal \{online\} 2021 \{cited November 2021\} Available from: http://www.iamj.in/posts/images/upload/2740_2745.pdf 